\title{
Abdominal Hydatidosis: Unusual and Usual Locations in a North Indian Population
}

\author{
Shreshtha Jain ${ }^{1}$, Sachin Khanduri ${ }^{1}$, Umar F. Sagar ${ }^{2}$, Poonam Yadav ${ }^{2}$, Mushahid Husain ${ }^{1}$, \\ Tariq Imam ${ }^{1}$ \\ 1. Radiology, Era's Lucknow Medical College and Hospital, Lucknow, IND 2. Radiology, Era’s Lucknow \\ Medical College and Hospital, Lucknow, IND
}

$\square$ Corresponding author: Shreshtha Jain, jain.shreshtha@yahoo.com

Disclosures can be found in Additional Information at the end of the article

\section{Abstract \\ Objective}

The objective of this study was to assess various locations in the abdomen wherein hydatid cysts can occur in an Indian population.

\section{Materials and methods}

A retrospective study was conducted on 38 patients of 20-55 years of age in an Indian population, who were diagnosed with hydatidosis on ultrasound and computed tomography. The measurement and location of the cysts were taken by the double operator method. Patients were followed up until post-surgical and histopathological diagnosis.

\section{Results}

Among the observed patients, the most common age group was 30-40 years (36.85\%), with male predominance (76\%). The most commonly involved organ was liver $(71.1 \%)$ followed by the kidney (10.5\%) and peritoneum (8\%), pancreas (2.6\%), spleen (2.6\%), common bile duct (2.6\%) and adnexa (2.6\%).

\section{Conclusion}

In spite of the usual presenting features, the locations of the cysts were unusual, thus warranting the importance of making the diagnosis before rupture of the cysts and thereby preventing life-threatening complications such as anaphylactic shock.

Received 03/06/2019 Review began 03/26/2019 Review ended 03/27/2019 Published 04/03/2019

\section{(c) Copyright 2019}

Jain et al. This is an open access article distributed under the terms of the Creative Commons Attribution License CC-BY 3.0., which permits unrestricted use, distribution, and reproduction in any medium, provided the original author and source are credited.
Categories: Radiology, Gastroenterology, General Surgery

Keywords: hydatid cyst, abdomen, indian population, unusual locations

\section{Introduction}

Hydatid disease is a zoonotic disease caused by the larvae of the cestode species of the genus Echinococcus, which includes E. granulosus, E. multilocularis, E. vogeli, and E. oligarthus [1]. Classical cystic echinococcosis (CE) is caused by E. granulosus complex. E. multilocularisis is responsible for alveolar echinococcosis, and E. vogeli causes polycystic echinococcosis [2].

CE has variable clinical presentations, ranging from asymptomatic diseases to acute emergencies. Hydatid cysts have been reported in various body organs such as the liver, lungs, 
peritoneum, bones, ovaries, breast, and the brain. Small, intact cysts have no specific characteristic symptoms. Clinical manifestations of this disease depend on multiple factors such as the organ involved, the site and size of the cyst, the interaction between the expanding cysts and the adjacent organ structures, complications related to cyst rupture, the spread of protoscoleces, and bacterial infections. In patients with infection or cyst rupture, the presentation may be severe [3-10].

Hydatid cysts most commonly involve the liver (in $59 \%$ to $75 \%$ of cases), followed by the lung (27\%). Involvement of the kidney (3\%), bone (1\% to $4 \%$ ), and brain ( $1 \%$ to $2 \%$ ) are not so common. Other sites such as the heart, spleen, pancreas, and voluntary muscle tissue are very rarely involved, but no site is immune [11-13].

The involvement of abdominal organs (e.g., the liver) is the most common, and therefore, most studies have been dedicated to hepatic hydatidosis or whole-body hydatidosis. However, scant literature is available regarding its presence in other abdominal organs like the pancreas, spleen, kidneys, peritoneum, common bile duct, and adnexa. Most cysts in these areas were unruptured and removed whole. To enhance our understanding of hydatid disease in unusual abdominal locations, we conducted this study in an Indian population to assess various locations in the abdomen wherein hydatid cyst can occur.

\section{Materials And Methods}

We conducted this retrospective study of patients aged 20 to 55 years at Era's Lucknow Medical College and Hospital in Lucknow, India from June 2016 to June 2018. The study included 38 patients who underwent ultrasonography and computed tomography (CT) at the radiology department of the hospital and were diagnosed with hydatidosis. Data collected included demographic information, clinical features, and laboratory findings. Patients allergic to contrast media, those with deranged renal functions, pregnant females, patients younger than 20 years, and patients not consenting for contrast study and surgical procedures were excluded from the study.

We located and measured the cysts using a double operator method. Axial and sagittal CT images were obtained, and measurements were taken accordingly. Patients were monitored via follow-up until the final post-surgical histopathological diagnosis of hydatid cyst.

\section{Results}

Thirty-eight patients were included in our study (Table 1), of whom 29 were men and nine were women. Being a tertiary care center, most patients came to our hospital from rural areas presenting with abdominal pain, abdominal lump, fever, and vomiting (Table 2). Two patients presented with concerns of obstructive jaundice as itching and yellowish discoloration of the eyes. The liver was the most commonly involved organ (Figure $1 ; 71.1 \%$ ), followed by the kidney (Figure 2; 10.5\%) and the peritoneum (Figure 1; 8\%) pancreas (Figure 3; 2.6\%), spleen (Figure $4 ; 2.6 \%$ ), common bile duct (Figure 5; 2.6\%), and adnexa (Figure 6; 2.6\%), as shown in Table 3. 


\section{Cureus}

\begin{tabular}{|c|c|c|c|}
\hline Age & Group & Number of Patients & Percentage \\
\hline $20-30$ & & 12 & $31.58 \%$ \\
\hline $31-40$ & & 14 & $36.85 \%$ \\
\hline $41-50$ & & 9 & $23.68 \%$ \\
\hline $51-55$ & & 3 & $7.89 \%$ \\
\hline
\end{tabular}

TABLE 1: Division of patients according to age

\section{Presenting Concern}

Pain in the abdomen

Abdominal lump

Fever

Vomiting

Jaundice

\section{Number of Cases}

27

15

5

8

2

TABLE 2: Presenting concerns 


\section{Cureus}

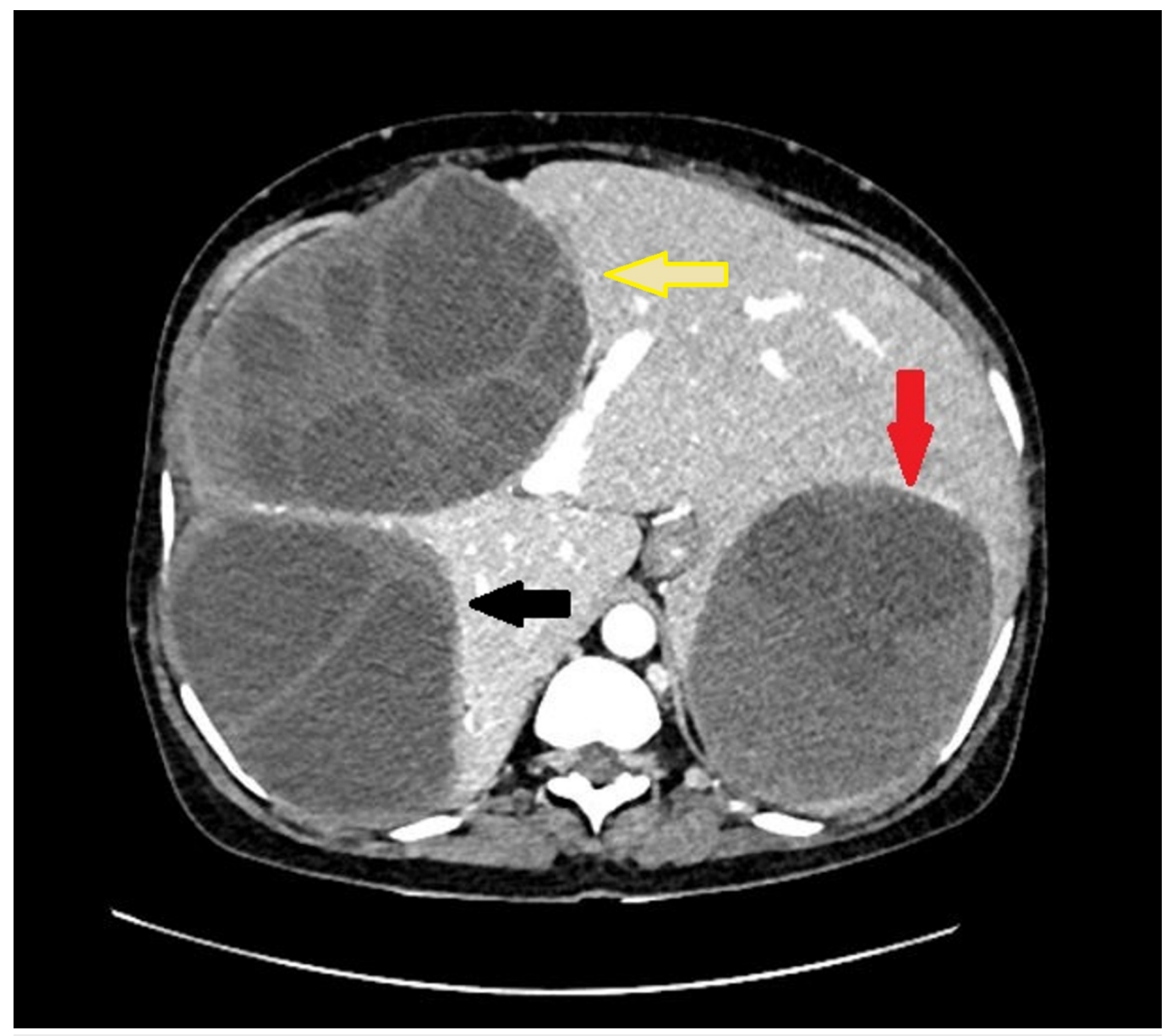

FIGURE 1: Hydatid cyst in the liver and peritoneum on CT

CECT abdomen axial image showing a large, well-defined hypodense lesion in the right lobe of the liver (black arrow) with mildly enhancing wall and internal septations. Similar hypodense lesion is seen in the left lobe of the liver (red arrow) with debris within and no septations. Another moderate-sized, well-defined, rounded cystic lesion with mildly enhancing walls and internal septations is seen in the peritoneum (yellow arrow) with scalloping of the adjacent liver margins. CECT: contrast-enhanced computed tomography, CT: computed tomography

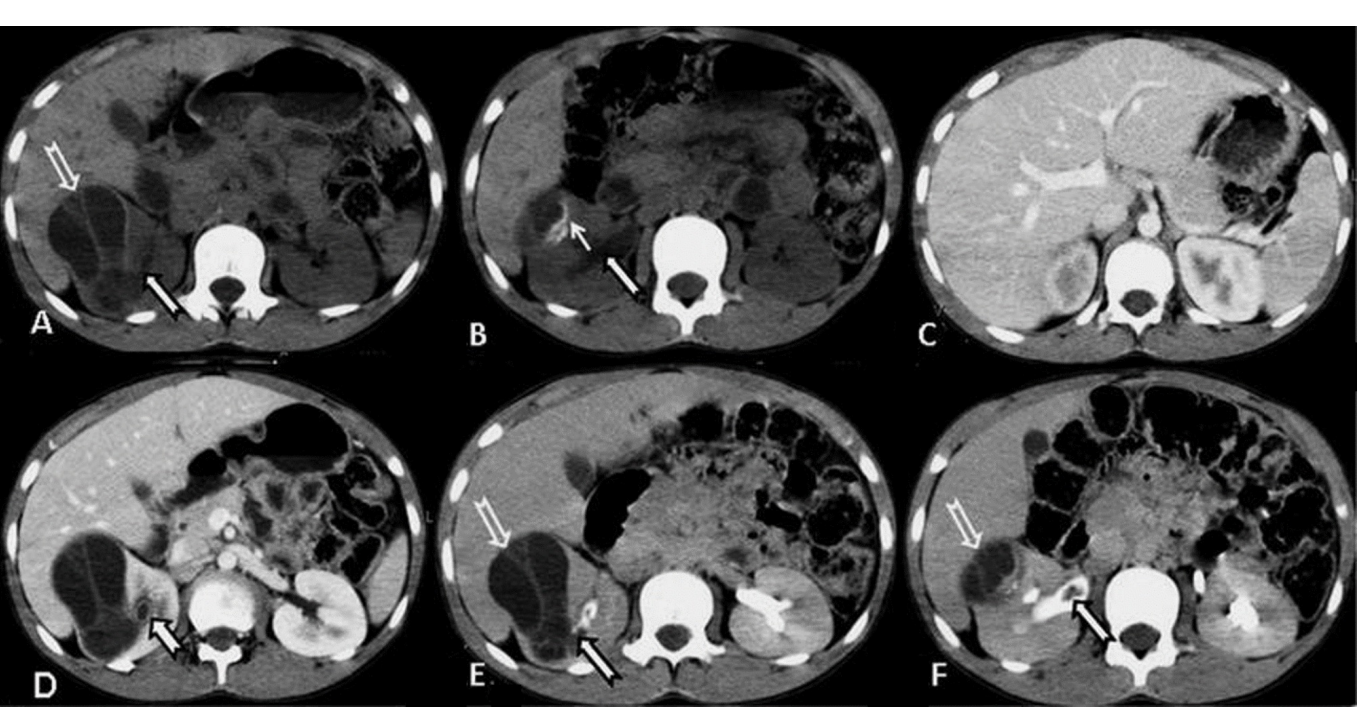

FIGURE 2: Hydatid cyst in the kidney on CT 


\section{Cureus}

Axial unenhanced $(A$ and $B)$, nephrographic $(C$ and $D)$, and excretory phase $(E$ and $F)$ images from a CT urogram demonstrate a moderate-sized, non-enhancing, low-attenuation,well-marginated, multi-septated cystic mass in the right kidney involving the outer cortex anterior to the renal pelvis (open white arrow) with peripheral calcifications dorsally (thin white arrow). Extension of the daughter cysts is noted in the right pelvicalyceal system extending into the right ureter which is suggestive of the rupture of the parent cyst (white arrow with black outline). CT: computed tomography

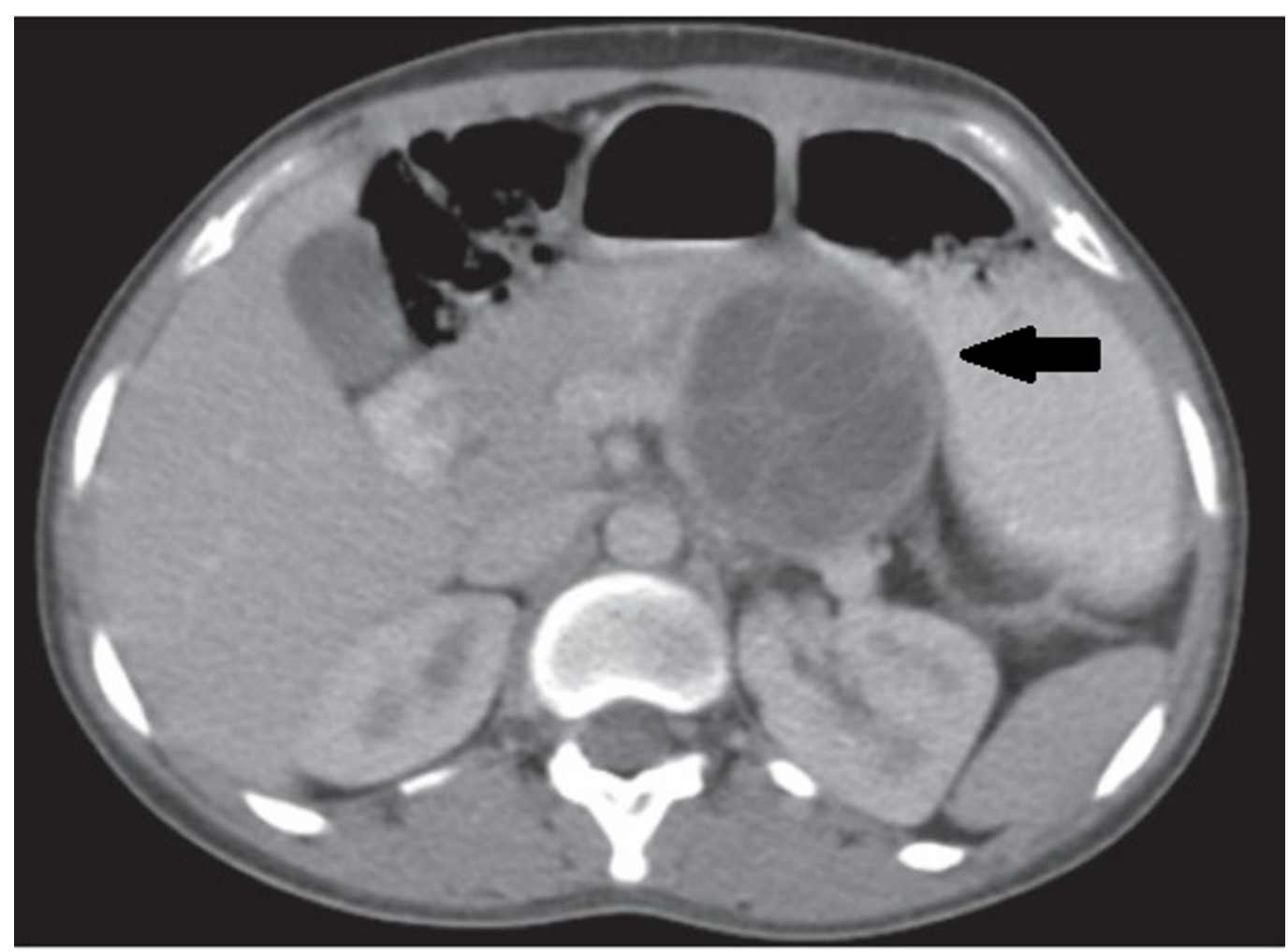

\section{FIGURE 3: Hydatid cyst in pancreas on CT}

Axial CECT image shows a moderate-sized, well-defined, lobulated, thin, mildly enhancing walled intrapancreatic cystic lesion in the distal body and tail region of the pancreas (black arrow). The lesion shows multiple, internal, well-defined cystic areas/daughter cyst/septations, with no evidence of calcification. Mass effect is seen on the spleno-pancreatic axis, and the splenic vein is compressed and narrowed. CECT: contrast-enhanced computed tomography, CT: computed tomography 


\section{Cureus}

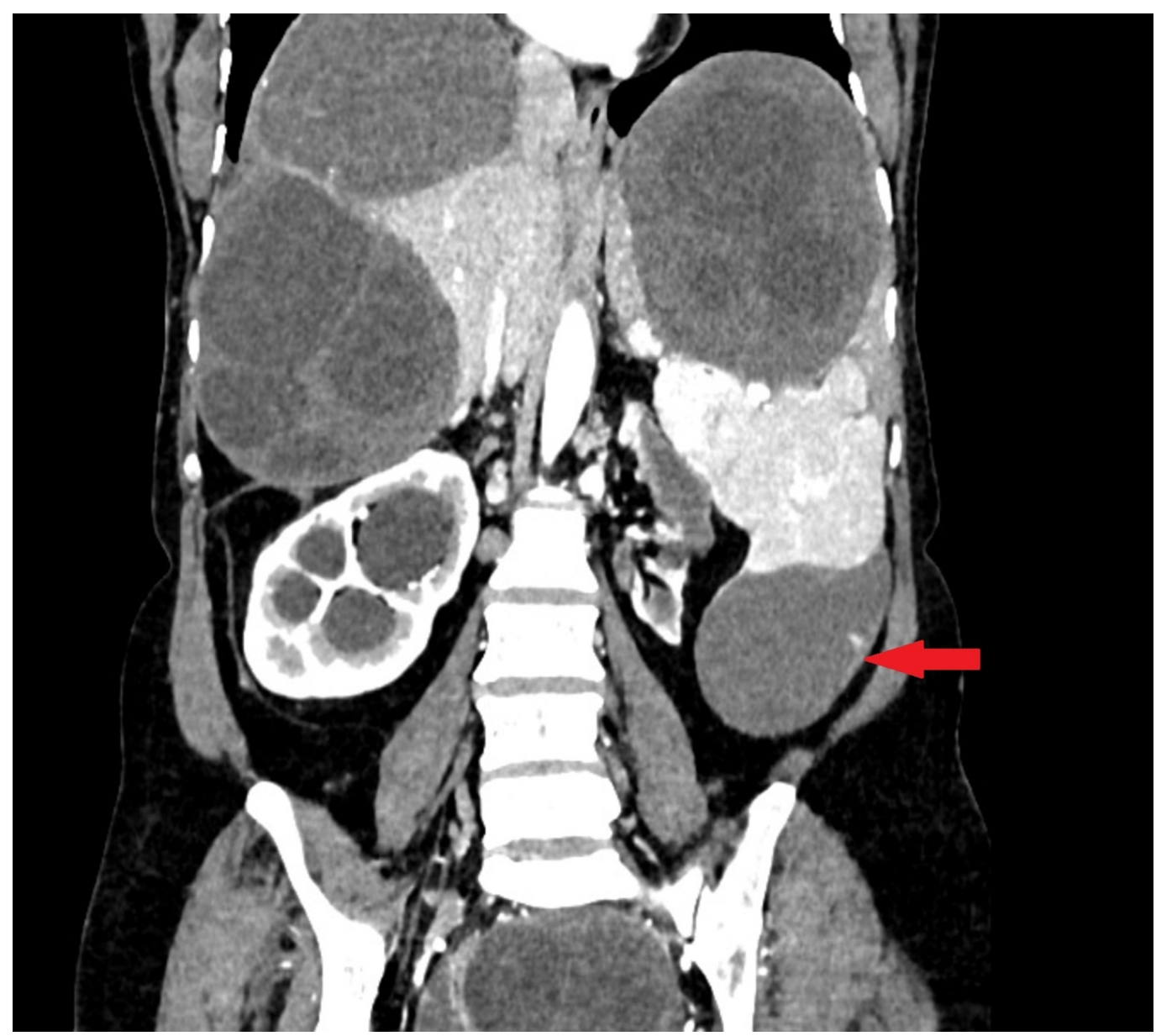

FIGURE 4: Splenic hydatid cyst on CT

CECT abdomen coronal image shows a moderate-sized, well-defined, rounded cystic lesion in the spleen (red arrow) with septation. CECT: contrast-enhanced computed tomography, CT: computed tomography 


\section{Cureus}

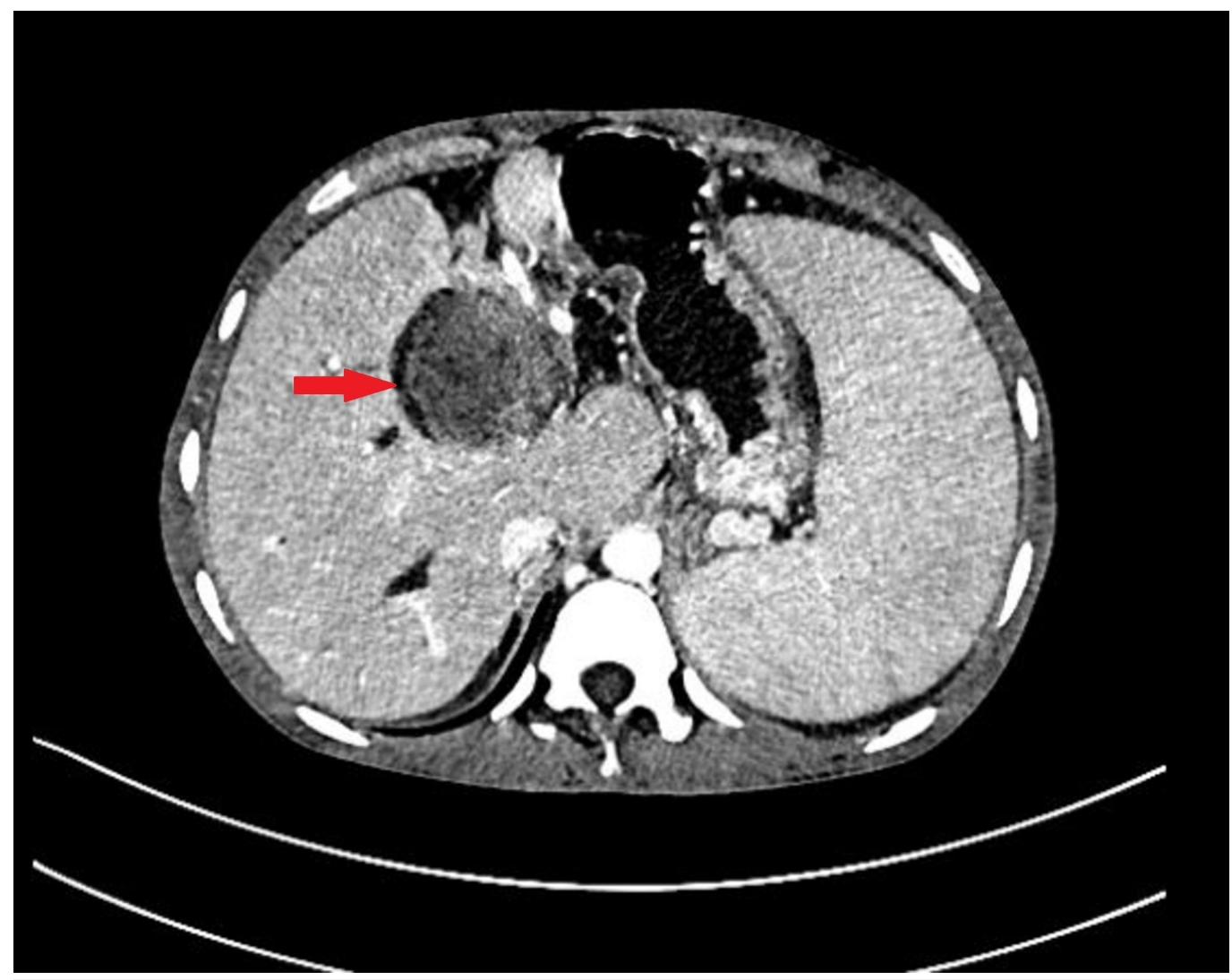

FIGURE 5: Hydatid cyst in the common bile duct on CT

CECT abdomen axial image shows a well-defined rounded heterogeneously hyperdense lesion (red arrow) with peripheral calcification at porta. CECT: contrast-enhanced computed tomography, CT: computed tomography

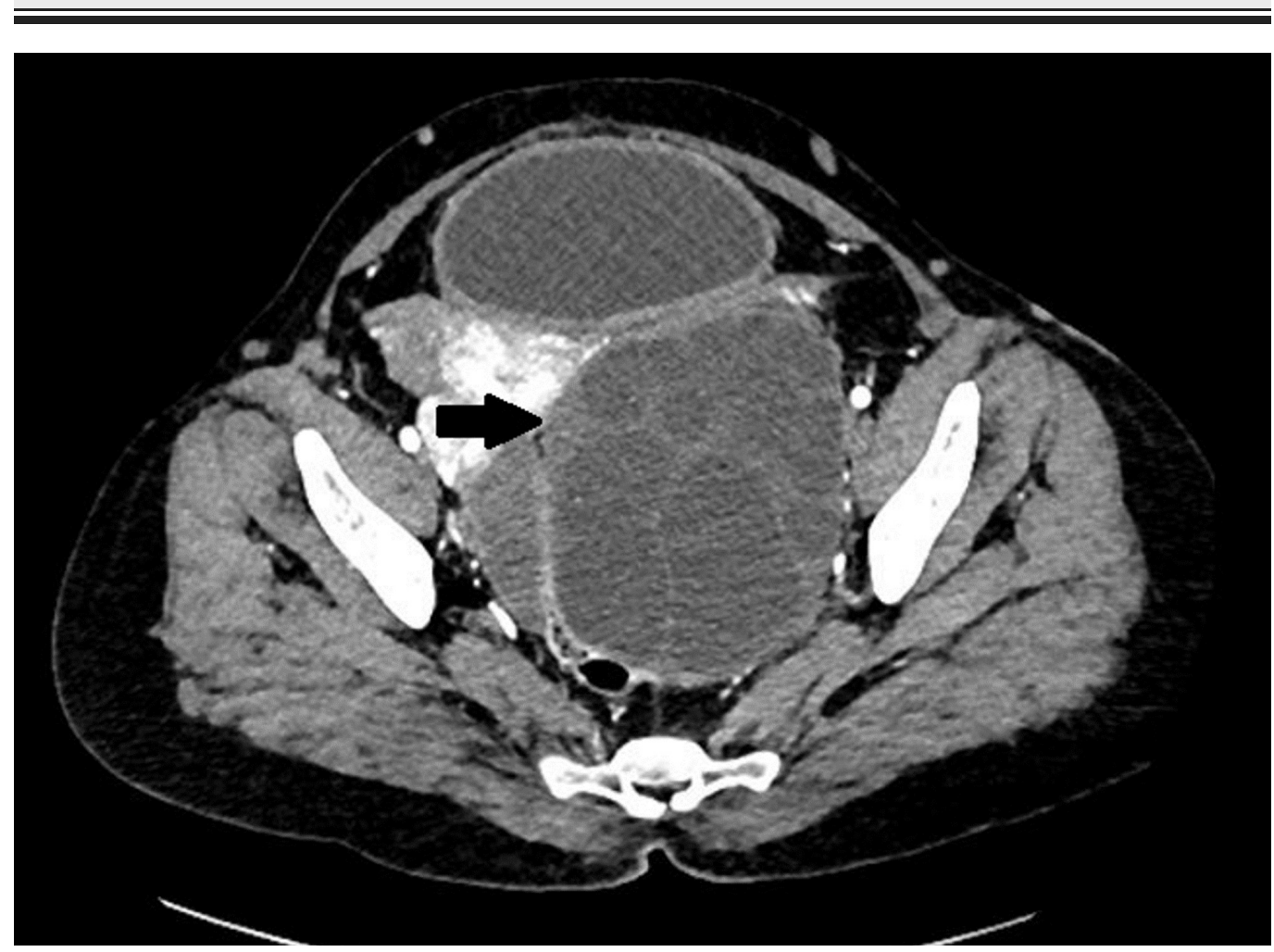




\section{Cureus}

\section{FIGURE 6: Adnexal hydatid cyst on CT}

CECT abdomen axial image shows a large, well-defined, rounded, thin-walled, multiloculated cystic lesion in the pelvic cavity on the left side. Left ovary is not visualized separately. CECT: contrastenhanced computed tomography, CT: computed tomography

\begin{tabular}{|c|c|c|c|c|}
\hline \multirow{2}{*}{ Location } & \multirow{2}{*}{ Number of patients } & \multirow{2}{*}{ Percentage } & \multicolumn{2}{|c|}{$95 \% \mathrm{Cl}$} \\
\hline & & & Lower & Upper \\
\hline Liver & 27 & 71.1 & 56.7 & 85.5 \\
\hline Kidney & 4 & 10.5 & 0.8 & 20.2 \\
\hline Peritoneum & 3 & 8 & 0.0 & 16.6 \\
\hline Pancreas & 1 & 2.6 & 0.0 & 7.7 \\
\hline Spleen & 1 & 2.6 & 0.0 & 7.7 \\
\hline Adnexa & 1 & 2.6 & 0.0 & 7.7 \\
\hline Common bile duct & 1 & 2.6 & 0.0 & 7.7 \\
\hline
\end{tabular}

\section{TABLE 3: Location of hydatid cysts}

\section{Discussion}

Hydatid disease is a unique parasitic disease endemic in many parts of the world. The parasite is echinococcus and has two hosts; the primary host is a carnivore such as a dog. Once the echinococcus cyst reaches the human liver, they grow to $1 \mathrm{~cm}$ in six months and then 2 to $3 \mathrm{~cm}$ annually thereafter, depending on the host's tissue resistance [14-16]. The liver is the first line of defense in the human body and therefore becomes the first organ to get involved before the cyst involves the other organs. The disease commonly involves the lungs and liver. However, unusual locations like the spleen, kidney, common bile duct, peritoneum, adnexa, and head of the pancreas have been reported [17-19].

Our study shows various unusual locations of abdominal hydatidosis in north Indian population and their clinical scenario and common features. Most of the patients in our study were aged 30 to 40 years, with a male predominance from rural communities of low socioeconomic status. The most common presenting feature in our cases was abdominal pain with lump. However, hydatid of the common bile duct and pancreas presented with the features of obstructive jaundice, and hydatid of the kidneys presented with the passage of small rounded white grape like structures in the urine.

Our study showed that, despite the usual presenting features, the locations of the cysts were unusual and warranted further investigation in the disease. Radiological studies of such cases also need more emphasis on commonly ignored locations such as the common bile duct, adnexa, and peritoneum, so that the diagnosis can be made before the cysts rupture, thereby preventing the patient from life-threatening complications such as anaphylactic shock. One of 
our cases illustrated timely radiological diagnosis of a hydatid cyst found in the common bile duct led to prompt surgical removal of the cyst, intact, and unruptured.

Our study has some notable limitations. Other studies on hydatid cysts have used various serological tests such as immunoelectrophoresis, enzyme-linked immunosorbent assay, latex agglutination, indirect hemagglutination, and polymerase chain reaction for diagnosing along with species specification of Echinococcus. We did not conduct these tests for species specification of Echinococcus, and we were unable to draw any relationship between different species of Echinococcus and other species more commonly responsible for hydatid cyst at usual and unusual locations in the abdomen.

\section{Conclusions}

Hydatid cysts can form in unusual, varied locations. Radiological studies of such cases should include less common locations such as the common bile duct, adnexa, and peritoneum, so that the diagnosis can be made before the cyst ruptures, preventing the patient from developing lifethreatening complications like anaphylactic shock.

\section{Additional Information \\ Disclosures}

Human subjects: Consent was obtained by all participants in this study. Animal subjects: All authors have confirmed that this study did not involve animal subjects or tissue. Conflicts of interest: In compliance with the ICMJE uniform disclosure form, all authors declare the following: Payment/services info: All authors have declared that no financial support was received from any organization for the submitted work. Financial relationships: All authors have declared that they have no financial relationships at present or within the previous three years with any organizations that might have an interest in the submitted work. Other relationships: All authors have declared that there are no other relationships or activities that could appear to have influenced the submitted work.

\section{References}

1. Richter J, Orhun A, Grüner B, et al.: Autochthonous cystic echinococcosis in patients who grew up in Germany. Euro Surveill. 2009, 14:1. 10.2807/ese.14.22.19229-en

2. Eckert J, Deplazes P: Biological, epidemiological, and clinical aspects of echinococcosis: a zoonosis of increasing concern. Clin Microbiol Rev. 2004, 17:107-35. 10.1128/CMR.17.1.107135.2004

3. Yalçinkaya I, Er M, Ozbay B, Uðrap S: Surgical treatment of hydatid cyst of lung: review of 30 cases. Eur Respir J. 1999, 13:441-4.

4. Khurana S, Das A, Malla N: Increasing trends in seroprevalence of human hydatidosis in North India: A hospital-based study. Trop Doct. 2007, 37:100-2. 10.1177/004947550703700215

5. Tiwary AK, Tiwary RN: Hydatid disease in Chotanagpur region of South Bihar . Indian J Surg. 1988, 50:14-8.

6. Nepalia S, Joshi A, Shende A, Sharma SS: Management of echinococcosis. J Assoc Physicians India. 2006, 54:458-62.

7. Sibal RN, Singh P: Hydatid disease in Himachal Pradesh . J Indian Med Assoc. 1974, 63:211-3.

8. Upadhyaya H, Rai P, Shah PK: Clinical study of hydatid disease in Jamnagar . J Indian Med Assoc. 1974, 63:213-6.

9. Riberio W: Hydatid disease in Jammu province . Indian J Surg. 1975, 37:244-8.

10. Reddy DB, Suvarnakumari G, Raju GC: Hydatid disease in Kurnool . J Indian Med Assoc. 1979, 63:5-8.

11. Safioleas M, Misiakos EP, Dosios T, Manti C, Lambrou P, Skalkeas G: Surgical treatment for lung hydatid disease. World J Surg. 1999, 23:1181-5.

12. Fazeli F, Narouie B, Firoozabadi MD, Afshar M, Naghavi A, Ghasemi-Rad M: Isolated hydatid 


\section{Cureus}

cyst of kidney. Urology. 2009, 73:999-1001. 10.1016/j.urology.2008.10.049

13. Yuksel M, Demirpolat G, Sever A, Bakaris S, Bulbuloglu E, Elmas N: Hydatid disease involving some rare locations in the body: a pictorial essay. Korean J Radiol. 2007, 8:531-40. 10.3348/kjr.2007.8.6.531

14. Beggs I: The radiology of hydatid disease . AJR Am J Roentgenol. 1985, 145:639-648. 10.2214/ajr.145.3.639

15. Lewall DB: Hydatid disease: biology, pathology, imaging and classification. Clin Radiol. 1998, 52:863-874. 10.1016/S0009-9260(98)80212-2

16. von Sinner WN: New diagnostic sign in hydatid disease: radiography, ultrasound, CT and MRI correlated to pathology. Eur J Radiol. 1990, 12:150-159. 10.1016/0720-048X(91)90119-G

17. Dagtekin A, Koseogles A, Kara E, Karabag H, Avci E, Tovun F, Bagdatoglu C: Unusual location of hydatid cysts in pediatric patients. Pediatr Neurosurg. 2009, 45:379-83. 10.1159/000260908

18. De U, Basu M: Hydatid cyst of common bile duct mimicking type I cholecochal cyst . J Indian Assoc Pediatr Surg. 2007, 12:83-4.

19. Gandopadhyay AN, Sahoo SP, Sharma SP, Gupta DK, Sinha CK, Rai SN: Hydatid disease in children may have an atypical presentation. Pediatr Surg Int. 2000, 16:89-90.

$10.1007 /$ s003830050024 